\title{
Uneven feet in a foal may develop as a consequence of lateral grazing behaviour induced by conformational traits
}

\author{
M. C. V. van HEEL*, A. M. KROEKenStOEL, M. C. van DIERENDONCK, P. R. van WEeREN and W. BACK \\ Derona Equine Performance Laboratory, Department of Equine Sciences, Faculty of Veterinary Medicine, Utrecht University, Yalelaan 12, \\ NL-3584 CM Utrecht, The Netherlands.
}

Keywords: horse; conformation; development; foal; laterality; uneven feet

\section{Summary}

Reasons for performing study: Conformational traits are important in breeding, since they may be indicative for performance ability and susceptibility to injuries.

Objectives: To study whether certain desired conformational traits of foals are related to lateralised behaviour while foraging and to the development of uneven feet.

Methods: Twenty-four Warmblood foals, born and raised at the same location, were studied for a year. Foraging behaviour was observed by means of weekly 10 min scansampling for $8 \mathrm{~h}$. A preference test (PT) was developed to serve as a standardised tool to determine laterality. The foals were evaluated at age 3,15, 27 and 55 weeks. The PT and distal limb conformation were used to study the relation between overall body conformation, laterality and the development of uneven feet. Pressure measurements were used to determine the loading patterns under the feet.

Results: About $50 \%$ of the foals developed a significant preference to protract the same limb systematically while grazing, which resulted in uneven feet and subsequently uneven loading patterns. Foals with relatively long limbs and small heads were predisposed to develop laterality and, consequently unevenness.

Conclusions: Conformational traits may stimulate the development of laterality and therefore indirectly cause uneven feet.

\section{Introduction}

Use of the horse has changed dramatically in the last 3-4 decades. The modern Warmblood horse that acts as a top athlete in various equestrian activities has evolved in less than 50 years from a much heavier and more robust, rustic horse that was mainly used in transport and agriculture. In the Netherlands, the old Dutch Warmblood breeds were cross-bred with Thoroughbreds and French and German Warmblood horses to produce a good sport horse. The Royal Dutch Warmblood Studbook (KWPN) is now one of the largest and best performing studbooks in the world, especially in the disciplines of show jumping and dressage. The most obvious conformational change has been the overall increase in height at the withers (HaW). For the KWPN, the average size increase over the past 25 years has been $0.1 \mathrm{~cm}$ per year $(\mathrm{n} \approx$ $85,000)$, resulting in a mean \pm s.d. HaW in 2000 of $165.9 \pm 3.0 \mathrm{~cm}$ (internal report, KWPN 2005). The domesticated horse is now the largest of the equidae, who range $120-140 \mathrm{~cm}$ with the exception of the Grevy's zebra whose average height is $155 \mathrm{~cm}$ (Nowak 1991; Duncan et al. 1992). A large, long-legged horse with a relatively small head is nowadays seen as optimal for sports activities and is the archetype of the 'beautiful horse' (Rosie 2005). However, apart from aesthetic considerations and functional aspects in terms of aptness for athletic performance, conformation is also important for soundness and durability (Holmström et al. 1990). In previous studies, it has been shown that distal limb conformation and the susceptibility to injuries are related (Balch et al. 1999; Ross and Dyson 2003; Anderson et al. 2004). Distal limb injuries are still the main reason for early retirement of sport horses (Kaneene et al. 1997). For this reason, horses with poor limb conformation are rejected at studbook admissions.

One commonly encountered fault is the occurrence of differently shaped and sized front feet (uneven feet), the clinical significance of which is unclear. Uneven feet are often related to lameness but are also commonly encountered at pre-purchase examinations in sound horses. Experimentally, the relationship between hoof angle and distal limb loading, especially loading of the deep and superficial digital flexor tendons and navicular bone, has been studied extensively (Thompson 1995; Wilson et al. 1998; Crevier-Denoix et al. 2001; Eliashar et al. 2004; Moleman et al. 2005). However, in most studies changes in hoof angle were artificially induced, resulting in a clearly broken hoof-pastern axis. In the case of uneven feet, hoof angles are different, but both feet are aligned in the pastern. Whether or not foot conformation is genetically determined or develops as a result of environmental influences is unknown, as is the relationship with asymmetries in locomotion pattern. Asymmetry in movement was shown to be present in Standardbred colts while trotting on a treadmill and was suggested to be an inherited trait since it increased with training (Drevemo et al. 1987). Back et al. (1995) showed that a foal's individual way of moving is very predictive for movement quality at mature age and concluded that gait quality is inherited. However, asymmetry can also result from lateralised behaviour, which has been shown to occur in horses, and which can vary for different tasks and sexes (Grzimek 1949; Meij and Meij 1980; McGreevy and Rogers 2005; Murphy et al. 2005). Laterality has 


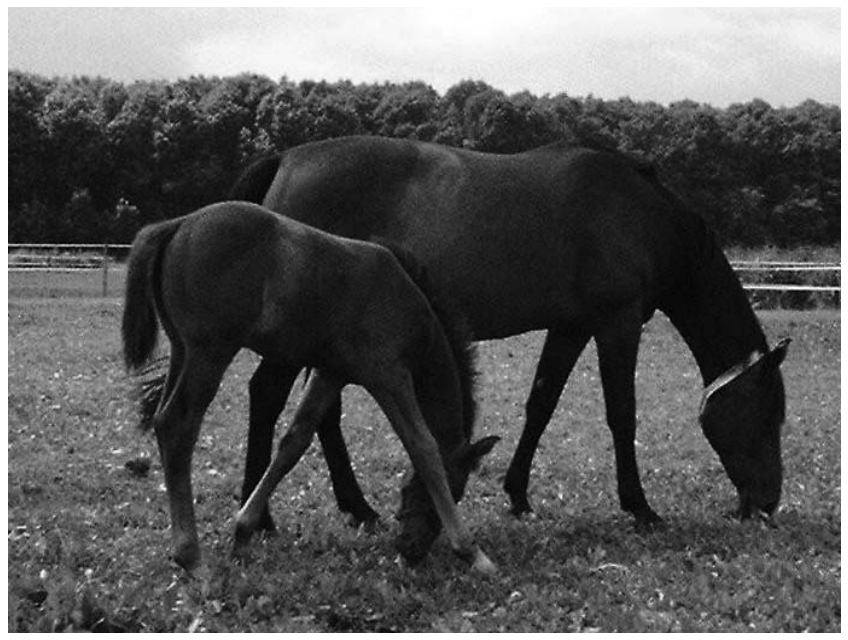

Fig 1: A foal grazing at pasture in the typical posture it has to adopt to reach the ground.

been shown in grazing Thoroughbreds (McGreevy and Rogers 2005 ) with $50 \%$ of horses consequently protracting the same limb.

In this study, the hypothesis was tested that the occurrence of uneven feet is related to the development of lateralised grazing behaviour in foals. Equidae are precocious animals and foals have to follow their dam within a few hours after birth. To keep up, the foal has a larger limb length to trunk height ratio than the mature animal (Keeling and Gonyou 2001). To reach the ground the foal has to spread its limbs, one in protracted position, the other in retraction. If this posture is consistently the same, with the same limb protracted, this lateralised behaviour may result in marked asymmetries that can affect both conformational traits, such as hoof-shape, and motor abilities. It is further hypothesised that desired conformational traits, such as relatively long legs and small heads, may predispose foals to develop lateral behaviour while grazing. If such asymmetries develop, they can be expected to hamper the ability to perform symmetrically, affecting the athletic capacity required to perform as easily on the left side as on the right. To study the development of laterality in foals while grazing and to detect if there is a relationship with conformational traits, 24 foals were observed in the field and while performing a custom-made preference test. Unevenness was quantified based on standardised conformational pictures. Pressure measurements were made to determine if unevenness of front feet resulted in intra-individual differences in pressure patterns. To assess whether intensive hoof care might prevent the development of unevenness $50 \%$ of the foals were trimmed regularly.

\section{Materials and methods}

\section{Animals}

Twenty-four Dutch Warmblood foals were studied, all born and raised in 2003 at the Institute for Horse Husbandry, Lelystad, The Netherlands. The foals were kept at pasture until October, when they were group-housed indoors at mean \pm s.d. $16.4 \pm 0.98$ weeks and were weaned at age $34.5 \pm 2.45$ weeks. The following spring the yearlings were returned to pasture.

\section{Behavioural study}

Observations were made from birth until weaning for one $8 \mathrm{~h}$ day/week by means of scan-sampling (Lehner 1979) every

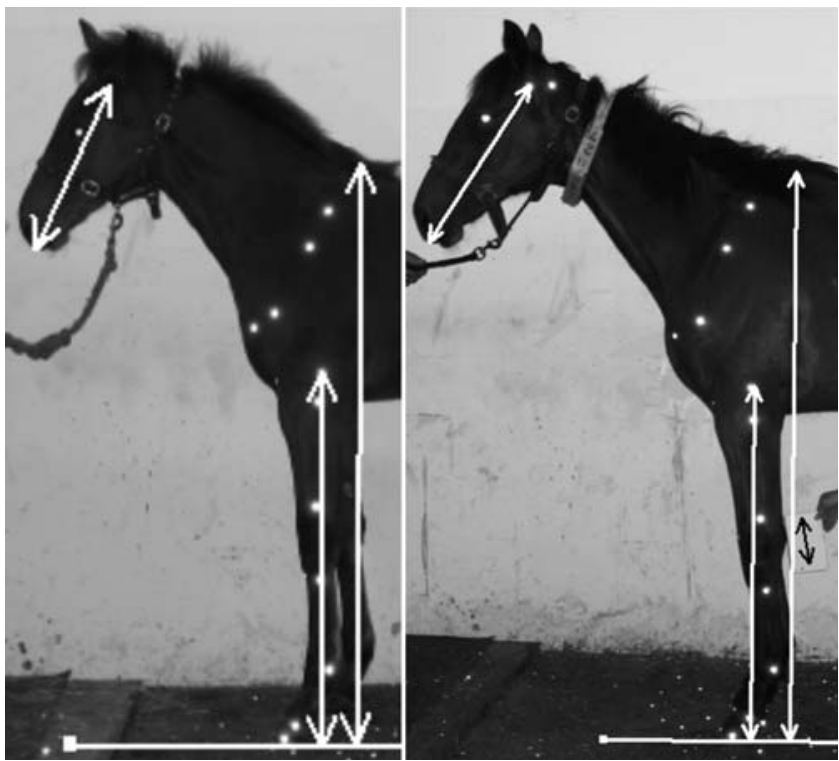

Fig 2: Two overall body conformation pictures of the same foal at 15 weeks (left) and at 55 weeks (right), reflective markers were placed on anatomical landmarks, the epicondyle of the humerus determined limb length and a marker on the base of the ear and unmarked tip of the nose were used to define head size.

$10 \mathrm{~min}$. Two persons were each assigned a group of 12 foals, which they observed during the $8 \mathrm{~h}$. When foraging, the only postures that contributed to the calculation to determine whether a preferred limb existed during that day were when the distance between the front feet exceeded 2 imaginary foal feet and both carpi were extended (Fig 1). The frequency a limb was placed protracted was determined and the daily ratio translated into Zvalues: (freq.left - freq.right) $/ \sqrt{ }($ freq.left + freq.right) to describe the existence as well as the strength of a preference while foraging. All values higher than 1.96 were considered significant.

\section{Preference test}

A standardised preference test (PT) was developed to encourage the foals to eat something from the ground and performed at individual ages 15,27 and 55 weeks. The foals had to reach the test area 15 times from varying distances. As a control measurement the foals were also triggered 5 times to eat something from a table. To enable measurements after the foals were tested, reference markers with known dimensions were placed in the field of view and the measurement test was recorded with digital video (Sony DCR TRV 20). The distance between front feet had to exceed the mean $+2 x$ s.d. of the control distance between the front feet to be scored as either left or right preference. A similar Z-value as in the observational data was calculated. The results of the PT at the age of 27 weeks were used to define 2 groups: Group $P$, with a significant preference, and Group NP, with no apparent preference; the presence of preference was controlled with a signtest. These 2 groups were then used to analyse other data before and after this age. Differences between the 2 groups were tested with a one-tailed Student's $t$ test and linearity tests were performed with linear regression analysis and calculating Pearson's correlation coefficient. All behavioural, conformational and centre of pressure $(\mathrm{CoP})$ data were checked for normality using a Shapiro-Wilk test. All analyses were performed in SPSS 10.0 with $\mathrm{P}<0.05$ as level of significance. 


\section{Conformation}

Standardised digital pictures (Canon, digital IXUS 400) of the front feet and legs were taken at ages 3, 15, 27 and 55 weeks. Total body conformation pictures were taken at 15 and 55 weeks. All pictures were taken perpendicular to the foal in the sagittal plane by the same operator (M.C.V.v.H.), who also placed reflective markers on anatomical landmarks to quantify a foal's conformation (Fig 2). The marker on the epicondyle of the humerus was used to define length of leg, and a marker on the base of the ear and unmarked tip of the nose were used to define head size. All pictures contained a scale marker to enable processing using image analysis software (Metron PX) ${ }^{1}$.

In the pictures of the feet, the hoof angle i.e. angle between the ground surface and the dorsal hoof wall, was determined (van Heel et al. 2005). Unevenness was defined by the relative intraindividual difference in hoof angle at 27 weeks; (right - left)/(right + left) $\mathrm{x} 100$. The foals with a value above mean were considered uneven, and all data were interpreted with this division. The ratios RL (leg length/height at the withers [HaW] x 100) and RH (head size/HaW x 100) were determined in the conformation pictures at 15 and 55 weeks (Fig 2). The analysis of the conformational data was performed with a one-tailed Student's $t$ test and linearity was tested with a backward regression analysis.

\section{Pressure measurements}

At 3, 15, 27 and 55 weeks, pressure measurements were performed underneath both front feet. Data were recorded at $250 \mathrm{~Hz}$ with an RsFootscan ${ }^{2}$ plate. Measurements were considered valid when the foal was standing quietly, with both limbs next to each other, and facing forward. Measurements were repeated 5 times and after each the foals had to step off the measurement system; the mean value of each measurement cycle was used in the analysis. The heart line of the central sulcus of the frog was indicated on the dorsal hoof wall to standardise the location of a scale marker, which was placed in front of each foot. This scale marker was used to determine the exact location of the CoP relative to the toe (Moleman et al. 2005). The pressure data were analysed with a one-tailed students $t$ test and linearity was tested with a regression analysis.

\section{Trimming}

One experienced farrier (G.B.) trimmed $50 \%$ of the foals at age 4, $8,12,18$ and 24 weeks. The conformational pictures, pressure measurements and preference test were always performed paired and 3 weeks after a foal had been trimmed. From age 28 weeks all foals were trimmed every 8 weeks. The foals had been divided into trim and nontrim groups by prestratification, with date of birth, sex and sire being the determinants of the strata.

\section{Results}

A preference developed in some of the foals and at 27 weeks $46 \%$ of the foals $(n=11)$ had adopted a significant preference to protract one limb, the right in 5 foals and the left in 6 (Table 1A). Preference test $(\mathrm{PT})$ results were predictive for the field data, since the correlations were very high (Table 1A), therefore the field served as validation for the PT and showed high correlation coefficients at all ages (Table 1A). Therefore, the results of the standardised preference test were used when further analysing the data. The foals in Group $P$ had a significantly larger distance

TABLE 1: Results of preference tests

\begin{tabular}{|c|c|c|c|c|c|}
\hline & & 3 weeks & 15 weeks & 27 weeks & 55 weeks \\
\hline \multirow[t]{3}{*}{ A } & Foals with a preference $(n=24)$ & - & 11 & 11 & 13 \\
\hline & Correlation field and PT & - & $0.82^{\star \star \star}$ & $0.79^{\star \star \star}$ & $0.78^{\star \star \star}$ \\
\hline & $\begin{array}{l}\text { Distance between front feet in PT } \\
(\mathrm{cm} \pm \text { s.e. })\end{array}$ & & $\begin{array}{l}\text { P: } 51.8 \pm 6.64^{* * *} \\
\text { NP: } 43.2 \pm 3.10^{\star \star \star}\end{array}$ & $\begin{array}{l}\text { P: } 52.2 \pm 6.99^{\star} \\
\text { NP: } 44.9 \pm 4.39^{\star}\end{array}$ & $\begin{array}{l}P: 48.6 \pm 5.55 \\
N P: 45.2 \pm 5.06\end{array}$ \\
\hline \multirow[t]{2}{*}{ B } & $\begin{array}{l}\text { Uneven hoof angulation } \\
\text { Mean difference in degrees } \pm \text { s.e. } \\
\text { Foals above mean }\end{array}$ & $\begin{array}{c}1.4 \pm 0.22 \\
11\end{array}$ & $\begin{array}{l}3.1 \pm 0.50 \\
10\end{array}$ & $\begin{array}{c}3.9 \pm 0.54 \\
11\end{array}$ & $\begin{array}{c}2.0 \pm 0.40 \\
10\end{array}$ \\
\hline & $\begin{array}{l}\text { Regression analysis PT and unevenness } \\
\text { R-square }\end{array}$ & - & $\begin{array}{c}0.73 \mathrm{Z}-\mathrm{PT}+0.53 \\
0.29^{\star \star}\end{array}$ & $\begin{array}{c}1.38 \mathrm{Z}-\mathrm{PT}+0.37 \\
0.58^{\star \star *}\end{array}$ & $\begin{array}{c}0.81 \mathrm{Z}-\mathrm{PT}+0.20 \\
0.62^{\star \star \star}\end{array}$ \\
\hline \multirow[t]{4}{*}{ C } & $\begin{array}{l}\text { Conformation } \\
\text { RL \% } \% \text { s.e. }\end{array}$ & - & $\begin{array}{l}P: 66.5 \pm 0.49^{* *} \\
\text { NP: } 65.0 \pm 0.27^{\star *}\end{array}$ & - & $\begin{array}{l}\text { P: } 61.9 \pm 0.17^{\star \star *} \\
\text { NP: } 60.5 \pm 0.22^{\star \star *}\end{array}$ \\
\hline & HaW $\mathrm{cm} \pm$ s.e. & - & $\begin{array}{l}P: 130.4 \pm 0.96 \\
N P: 128.7 \pm 0.86\end{array}$ & - & $\begin{array}{l}\text { P: } 155.8 \pm 0.88^{*} \\
\text { NP: } 152.6 \pm 0.97^{*}\end{array}$ \\
\hline & $\mathrm{RH} \% \pm$ s.e. & - & $\begin{array}{l}\text { P: } 30.0 \pm 0.48^{*} \\
\text { NP: } 31.5 \pm 0.61^{*}\end{array}$ & - & $\begin{array}{l}P: 31.7 \pm 0.45 \\
N P: 32.4 \pm 0.54\end{array}$ \\
\hline & $\begin{array}{l}\text { Backward regression analysis: } \\
\text { Z-PT27 = RL and/or RH and/or HaW } \\
\text { R-square }\end{array}$ & - & $\begin{array}{c}0.49 \mathrm{RL}-0.24 \mathrm{RH}-22.90 \\
0.48^{\star \star \star}\end{array}$ & - & $\begin{array}{c}1.02 \mathrm{RL}-60.17 \\
0.51^{\star *}\end{array}$ \\
\hline \multirow[t]{2}{*}{ D } & $\begin{array}{l}\text { Location of CoP } \\
\text { Mean difference in } \mathrm{mm} \pm \text { s.e. }\end{array}$ & $\begin{array}{l}U: 3.2 \pm 0.96 \\
E: 3.1 \pm 0.59\end{array}$ & $\begin{array}{l}U: 4.6 \pm 0.70 \\
E: 3.6 \pm 0.98\end{array}$ & $\begin{array}{l}U: 2.8 \pm 0.60 \\
E: 3.0 \pm 0.63\end{array}$ & $\begin{array}{l}\mathrm{U}: 3.2 \pm 0.65^{*} \\
\mathrm{E}: 1.5 \pm 0.30^{*}\end{array}$ \\
\hline & $\begin{array}{l}\text { Regression analysis: location of CoP and HA } \\
\text { R-square }\end{array}$ & $\begin{array}{c}\mathrm{ns} \\
0.01\end{array}$ & $\begin{array}{c}-0.56 \mathrm{HA}+71.4 \\
0.20^{\star \star}\end{array}$ & $\begin{array}{l}-0.62 \mathrm{HA}+72.0 \\
0.24^{\star \star *}\end{array}$ & $\begin{array}{c}-0.91 \mathrm{HA}+94.4 \\
0.34^{\star \star \star}\end{array}$ \\
\hline
\end{tabular}

$(\mathrm{N}) \mathrm{P}=(\mathrm{no})$ preference; $\mathrm{PT}=$ preference test $\mathrm{RL}=$ leg length/HaW; HaW = Height at the withers; $\mathrm{RH}=$ head size/HaW; Z-PT $(27$ weeks $)=\mathrm{Z}$-value preference test $\left(27\right.$ weeks); $\mathrm{CoP}=$ centre of pressure; $\mathrm{HA}=$ hoof angle; $\mathrm{U}=$ uneven feet $\left(27\right.$ weeks); $\mathrm{E}=$ even feet $\left(27\right.$ weeks); ns = not significant at $\mathrm{P}<0.05$; ${ }^{*} \mathrm{P}<0.05$; ${ }^{* *} \mathrm{P} \leq 0.01 ;{ }^{* * *} \mathrm{P} \leq 0.001$. 


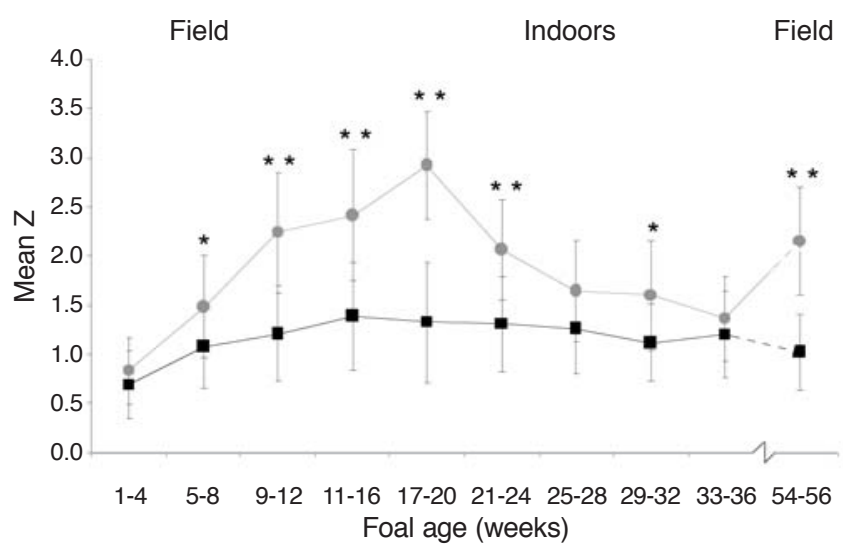

Fig 3: Development of a preference in the field over time (mean Z-value at $y$-axis)..$=$ foals with a preference in the preference test $(P T)$ at age 27 weeks $(n=13)$. $\mathbf{\square}$ = foals without a preference in the PT at age 27 weeks $(n=11)$. Error bars represent s.d.

between their front feet when reaching to the ground at age 15 and 27 weeks (Table 1A).

The relationship between a preference and an undesired conformational trait became apparent in the front feet of the foals, with Group $P$ developing more unevenness in hoof angle. Where Group $P$ already had a significant level of preference in the field before age 12 weeks (Fig 3), there was still no significant difference in unevenness between the 2 groups at age 15 weeks. However, at age 27 weeks the unevenness was significantly different $(\mathrm{P}=0.022)$ with mean \pm s.e. $5.2 \pm 0.47$ degrees in Group $P$ double that of Group NP $(2.6 \pm 0.47$ degrees $)$. That unevenness developed as a consequence of laterality was supported by the increasing strength in linearity between preference and unevenness (Table 1B). Furthermore, the regression analysis showed that the foot placed in front in the PT was the foot with the lowest hoof angle (Fig 4).

There was also a linear relationship between desired conformational traits and development of preference. The linear regression analysis made clear that the 2 significant factors that explained the strength of a preference, the Z-value, were ratios of head size (RH; head length/height at withers $[\mathrm{HaW}])$ and leg length (RL; leg length/HaW). At age 55 weeks, only RL remained a significant factor in the equation and, although RL decreased in all foals, the difference between the 2 groups remained significant. The difference between Group P and Group NP was significant for both RL and RH at age 15 weeks. At age 55 weeks Group $P$ not only had relatively longer legs but their $\mathrm{HaW}$ was also larger (Table 1C).

The negative influence of unevenness, in a functional sense, is illustrated by the development of different loading patterns in the front feet of individuals with uneven feet. At age 3 weeks there was no significant relationship between hoof angle and location of the centre of pressure $(\mathrm{CoP})$, but afterwards the relationship became increasingly strong (Table 1D). With a decrease in hoof angle the distance of the CoP to the toe increased. The intraindividual difference between the locations of the CoP relative to the toe in both feet was significantly different between foals with even and uneven feet at 55 weeks $(P=0.044)$.

Correction by regular trimming did not have any significant effect on the development of unevenness, nor did it prevent the development of a preference. In the trimmed group, 6 foals developed unevenness, with 3 having the lowest hoof angle in the

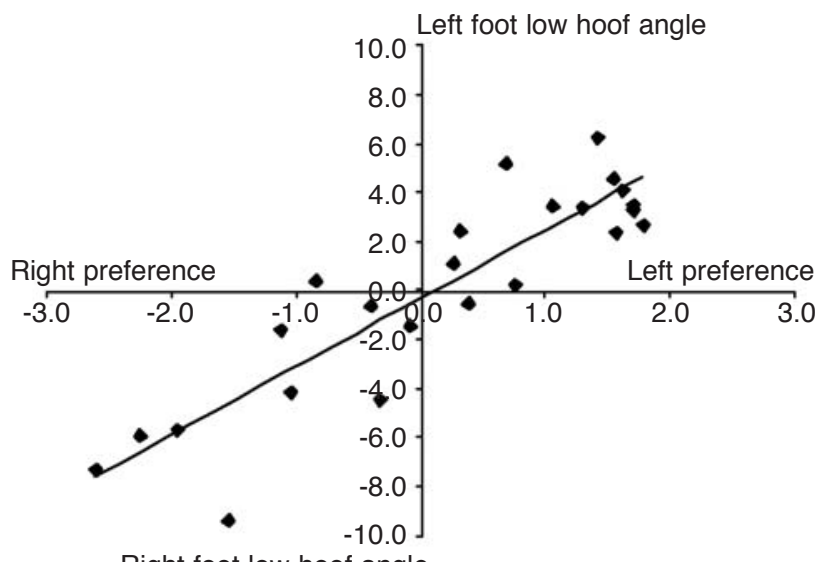

Right foot low hoof angle

Fig 4: Relationship $(r=0.89)$ between the strength of preference during field observations and the degree of unevenness. On the $x$-axis the results of preference in the field, expressed as mean Z-value; on the $y$-axis unevenness in hoof angle at 27 weeks. Note that the Z-value is below the level of significance (1.96) in the majority of foals, which results from the inclusion of all observations of the first 31 weeks. In this period laterality developed and was not yet present in the first weeks. Inclusion of these observations decreased the mean Z-value while leaving the relationship of preference and hoof angle unaltered.

left. In the nontrimmed group 5 foals developed unevenness, with 2 having the lowest hoof angle on the left. In the trimmed group, 5 foals developed a preference and in the nontrimmed group 6 foals. There was one foal with uneven feet and without a preference and one foal with a preference but without unevenness. The mean unevenness decreased in both groups when all the foals were trimmed on a regular base after age 28 weeks, but at about the same time they were also housed indoors where they were fed from a surface higher than ground level.

\section{Discussion}

Very young foals randomly adopted different postures to graze, often flexed in one or both carpi, or with both front limbs in a more abducted position. When they became older and grazed more, the typical posture of widely spreading the front limbs in the sagittal plane became apparent. In this study $46 \%$ of the foals developed laterality while grazing; the foals with a preference at 27 weeks, Group $P$, reached the level of significance in the field already before age 12 weeks. The preference test correlated very strongly with the field observations at all ages and can, therefore, be interpreted as an easy and reliable tool to determine laterality. Foals with relatively long limbs and a small head were forced to spread their limbs further apart and turned out to be more prone to develop laterality. As a result of the preference, foals developed more unevenness in their feet with the hoof that was placed in protracted position becoming the hoof with the lowest hoof angle. Eventually the unevenness in feet resulted in uneven loading patterns.

The relationship between hoof angle and limb loading has been addressed in previous studies (Thompson 1995; Wilson et al. 1998; Crevier-Denoix et al. 2001; Eliashar et al. 2004), in which a clear effect was shown. Most of these studies used artificial devices to provoke an exaggerated effect, but Moleman et al. (2005), studied the effects of a standard shoeing interval on the intra-individual difference in distal limb loading in sound 
horses, and showed that even slight unevenness may result in significantly different limb loading after an 8-week shoeing interval. Epidemiological studies investigating the long-term effects of uneven feet and uneven loading patterns are lacking, but it can be conjectured that this condition might lead to a predisposition to overload injuries at mature age.

Apart from the development of unevenness and the possible increase in susceptibility to injury, there are other aspects of the development of laterality that might affect the horse's performance or soundness. Most of today's sport horses have to perform symmetrically, and thus have to be able to turn as easily left as right. Any form of lateralised behaviour could influence the ability to perform symmetrically. Another concern is the possible influence of laterality in young fast growing musculoskeletal tissues. During growth, tissue architecture and composition are to a large extent determined by biomechanical loading with form following function. This mechanism has since long been recognised to exist in bone (Wolff 1892), but received increasing attention in other tissues that are more crucial to equine health and longevity, such as articular cartilage and tendons (Brama et al. 2000). Laterality present at such young age might therefore affect not only the ability to perform symmetrically at mature age but also negatively influence tissue quality.

Correction of the feet by regular trimming was not enough to prevent the development of unevenness in foals. Making a correction every 4-8 weeks is probably insufficient to alter the hoof angulation in feet that consistently have different loading for a substantial part of the day. It should be emphasised that none of these foals were lame or were born with serious limb deformities; this observation does not question the efficacy of trimming foals with such problems (Ross and Dyson 2003). The unevenness decreased in both groups when all the foals were trimmed regularly after age 28 weeks, but at about the same time they were also housed indoors where they were fed from a surface higher than ground level, blocking stance at the shoulder with a feeding grid. Due to the difference of feeding practices indoors, the foals were less triggered to forage in the group housing area. Hence, the number of observed foraging postures was lower, decreasing the chance to detect significant preferences. Nevertheless, the correlation between the situations in the field and indoors was very strong. The PT showed that preferred postures were still present. When back at pasture the next season, preferences were the same, in the field and according to the PT, indicating that the development of laterality in foals is a process that is relevant for later life.

To define when 2 feet are uneven remains a matter of dispute and the results of this study cannot simply be extrapolated to mature horses, since there might be other reasons for mature horses and foals developing unevenness, such as pain. Furthermore, in this study foals were defined as uneven when the intra-individual variation in hoof angulation was above the mean variation within the random sample. The differences measured in this study might represent a natural variation and not a pathological disorder. The scope of this study was to ascertain whether overall body conformation, laterality and development of feet were related and not to give a definition of uneven feet. In order to assess the clinical relevance of unevenness it is imperative to know from which level unevenness may lead to problems such as loss of performance or an increased incidence of injuries.

Notwithstanding these limitations, it seems clear that the excessive development of laterality should be seen as an undesired trait in modern sport horses. Prevention of such a development would be the best solution. Housing foals indoors is a theoretical option, but can never be a solution because free pasture exercise is essential for the sound development of musculoskeletal tissues (Goodship and Birch 2001; Brama et al. 2002).

Other adaptations in management could be made, such as specific training of individual foals, based on the outcome of a preference test, or changing pasture management. Instead of pasturing foals in a rich short-cut pasture, as is commonly done, they could be placed in pastures with less and higher grasses to encourage them to walk more and prevent the strong trigger to eat from ground level.

However, and most importantly, the reason for a foal developing a preference should be taken into account. Breeding policies aim at producing an equine athlete that performs well and 'looks nice'. Some of the conformational characteristics are based on aesthetic considerations only, or their influence on performance has not been well established. For instance the influence of HaW on performance and gait quality has been studied, but with contradictory results. Limb length and $\mathrm{HaW}$ did not correlate with stride length or frequency in foals up to age of 6-8 months (Leach and Cymbaluk 1986) and Dušek et al. (1970) reported the same for adult horses. Galisteo et al. (1998) found a positive but rather weak correlation of 0.51 between $\mathrm{HaW}$ and stride length and Holström et al. (1990) that elite show jumping horses had a significantly larger $\mathrm{HaW}$. In this study the foals at 55 weeks with uneven feet had a significantly larger HaW. This might indicate that there is not only an optimal size for equidae in the wild, but also for today's equine athlete. In this respect it is important to realise that breeding for beauty in horses might negatively affect athletic performance.

\section{Acknowledgements}

The authors would like to thank Dr. P. Meeus for his advice and input at the onset of this experiment and $\mathrm{H}$. van Wijk of the Department of Biostatistics for his expert advice on the statistical analyses in this study. We would further like to thank G. Bronkhorst for trimming all foals and last but not least all the students, who helped with the data acquisition (especially for the many hours in the field, watching foals) M. Grijpstra, R. Makkinga, C. Stampraad, W. Kapteijn, M. Knies, A. Koppens, M. Boumans, H. Maas, S. Teunissen, R. de Leeuw, D. Staller, S. van Groeningen and M. Rietbeek.

\section{Manufacturers' addresses}

${ }^{1}$ Epona Tech, Creston, California, USA.

${ }^{2}$ RsScan international, Olen, Belgium.

\section{References}

Anderson, T.M., McIlwraith, C.W. and Douay, P. (2004) The role of conformation in musculoskeletal problems in the racing thoroughbred. Equine vet. J. 36, 571-575.

Anon (2005) KWPN Internal Report. KWPN, Harderwijk. pp 1-3.

Back, W., Schamhardt, H.C., Hartman, W., Bruin, G. and Barneveld, A. (1995) Predictive value of foal kinematics for the locomotor performance of adult horses. Res. vet. Sci. 59, 64-69.

Balch, O., White, K., Butler, D. and Metcalf, S. (1995) Hoof balance and lameness: Improper toe length, hoof angle and mediolateral balance. Comp. cont. Educ. pract. Vet. 17, 1275-1283.

Brama, P.A., Tekoppele, J.M., Bank, R.A., Barneveld, A. and van Weeren, P.R. (2000) Functional adaptation of equine articular cartilage: the formation of regional biomechanical characteristics up to the age of one year. Equine vet. J. 32, 217-221. 
Brama, P.A., Tekoppele, J.M., Bank, R.A., Barneveld, A. and van Weeren, P.R (2002) Biomechanical development of subchondral bone from birth until age eleven months and the influence of physical activity. Equine vet. J. 34, 134-149.

Crevier-Denoix, N., Roosen, C., Dardillat, C., Pourcelot, P., Jerbi, H., Sanaa, M. and Denoix, J.M. (2001) Effects of heel and toe elevation upon the digital joint angles in the standing horse. Equine vet. J., Suppl. 33, 74-78.

Drevemo, S., Fredricson I. and Hjertén, G. (1987) Early development of gait asymmetries in trotting Standardbred colts. Equine vet. J. 19, 189-191.

Duncan, P., Ryder, O., Asa, C.H. and Feh, C. (1992) The nature and value of zebras, asses and horses. In: Zebras, Asses and Horses. An Action Plan for the Conservation of Wild Equids. Ed: P. Duncan, IUCN/SSC Equid Specialist Group, IUCN, Gland. pp 1-5.

Dušek, J., Erhein, H-J. and Engelhardt, W. (1970) Beziehungen zwischen Trittlange, Trittfrequenz und Geschwindigkeit bei Pferden. Z. Tierz. Zuchtungsbiol. 87, 177-188.

Eliashar, E., McGuigan, M.P. and Wilson, A.M. (2004) Relationship of foot conformation and force applied to the navicular bone of sound horses at the trot. Equine vet. J. 36, 431-435.

Galisteo, A.M., Cano, M.R., Morales, J.L., Vivo, J. and Miró, F. (1998) The influence of speed and height at the withers on the kinematics of sound horses at the handled trot. Vet. Res. Commun. 22, 415-423.

Goodship, A.E. and Birch, H.L. (2001) Exercise effects on the skeletal tissues. In: Equine Locomotion, Eds: W. Back and H.M. Clayton, W.B. Saunders, London. pp 227-250.

Grzimek, B., (1949) Rechts und Linkshändigkeit bei Pferden, Papageien und Affen. Z. Tierpsychol. 6, 406-432.

Holmström, M., Magnusson, L.E. and Philipsson, J. (1990) Variation in conformation of Swedish Warmblood horses and conformational characteristics of élite sport horses. Equine vet. J. 22, 186-193.

Kaneene, J.B., Ross, W.A. and Miller, R. (1997) The Michigan equine monitoring system. II. Frequencies and impact of selected health problems. Prev. vet. Med. 29, 277-292.

Keeling, L.K., and Gonyou, H.W. (2001) Social behaviour in farm animals. Cabi Publishing, Oxford. pp 59-89.
Leach, D. and Cymbaluk, N.F. (1986) Relationships between stride length, stride frequency, velocity and morphometrics of foals. Am. J. vet. Res. 9, 2090-2097.

Lehner, P N. (1979) Handbook of Ethological Methods. Series in Ethology, Ed: G.M. Burghart, Garland STPM Press, New York. pp 1-403.

McGreevy, P.D. and Rogers, L.J. (2005) Motor and sensor laterality in thoroughbred horses. Appl. anim. behav. Sci. 90, 337-352.

Meij , H.S. and Meij, J.C.P. (1980) Functional asymmetry in the motor system of the horses. S. Afr. J. Sci. 76, 552-556.

Moleman, M., van Heel, M.C.V., van Weeren, P.R. and Back, W. (2005) Hoof growth between two shoeing sessions leads to a substantial increase of the moment on the distal, but not on the proximal interphalangeal joint. Equine vet. J. 38, 170-174.

Murphy J., Sutherland, A. and Arkins, S. (2005) Idiosyncratic motor laterality in the horse. Appl. anim. behav. Sci. 91, 297-310.

Nowak R.M. (1991) Walker's Mammals of the World, 5th edn., John's Hopkins U.P., Baltimore. pp 484-486.

Rosie, D.W. (2005) Het Dressuurpaard - exterieur-bewegingen-ziel. Fontaine Uitgevers, 's Graveland. pp 1-16.

Ross, M.W. and Dyson, S.J. (2003) The foot and shoeing. In: Diagnosis and Management of Lameness in the Horse, W.B. Saunders, St Louis. pp 250-275.

Thompson, K.N. (1995) Hoof conformation and toe angle: influences on joint angles and lower limb strains. Equine Athlete 8, 8-11.

van Heel, M.C.V., Moleman, M., Barneveld, A., van Weeren, P.R. and Back, W. (2005) Changes in location of centre of pressure and hoof-unrollement pattern in relation to an 8-week shoeing interval in the horse. Equine vet. J. 37, 536-540.

Wilson, A.M. Seelig, T.J. Shield, R.A. and Silverman, B.W. (1998) The effect of foot imbalance on point of force application in the horse. Equine vet. J. 30, 540-545.

Wolff, J. (1892) Das Gesetz der Transformation der Knochen. Berlin, Hirschwald. pp 101-116.

Author contributions Initiation, conception and planning of this study were by M.C.V.v.H. and W.B. Its execution and statistics were by M.C.V.v.H., A.M.K. and M.C.v.D. All authors contributed to the writing. 